generally greater when there is-as in the case of the oyster-a metamorphic stage in the development, at which stage there is generally a very great mortality. Academic researches on rearing marine animals have, however, been made only on a small scale, and additional difficulties arise when it is necessary to carry out experiments in a large volume of unchanged-but changing-water.

In recent years the Government Fisheries Department has attacked the problem of the artificial production of oysters in the mussel purification tanks at Conway, with variable, but probably greater, success than has attended previous efforts. The Government experiments were begun on empirical lines in the post-War period, but are now being continued on a scientific plan, ${ }^{14}$ which is taking into account all the factors likely to affect a successful issue, such as nature of the larval food, constituents of the water, enemies, as well as temperature conditions; ultimate success in obtaining falls of millions of spat is probably only a question of time. The recent recognition of the importance of the minor chemical constituents ${ }^{15}$ of sea-water, especially in a stationary body of water, has widened the scope of these experiments, but at the same time narrows down the possible.unknown factors. The problem is thus expanding beyond the province of the biologist, and whether the original staff is big enough-even with hearty outside co-operation-to press the investigation with vigour may be reasonably doubted.

The original idea of these experiments was to discover whether oysters could be produced in bulk in tanks on a commercial scale. Oysters have been produced in large quantities, but the commercial aspect has not yet been sufficiently considered. Millions of oysters may be procured in tanks, but unless a reasonable proportion are eventually put on the market at a profit, the project is commercially unsound. It is desirable, therefore, that a largescale commercial experiment should be carried out side by side with investigations into the exact conditions for ensuring a large spatfall.

\section{Artifictal Fattening.}

The success of continental cultivators in fattening oysters artificially leaves no doubt that the same process-if commercially desirable-could be carried out in England by supplying a superabundance of diatoms in tanks or ponds. Such oysters are, however, usually green-gilled, and are not favoured by the English consumer, so that the problem in artificial fattening in England would comprise also the production of a white 'fish.'
Recent researches, ${ }^{10}$ however, indicate that a superabundance of diatoms and/or peridianians might be obtained in closed estuarine waters by artificially maintaining the slight concentration of essential foodstuffs, phosphates and nitrates, necessary for heavy crops of this planktonic vegetation. Supplied with abundant food of this nature, oysters would fatten naturally and with a minimum of outlay on labour.

\section{Research Problems.}

The main research problems in connexion with oyster culture are those concerned with increasing the stock of young individuals and with fattening oysters for the market. While the artificial production of young oysters may eventually be an assured commercial proposition, it is possible that slight improvements in the methods of securing oyster-spat on the natural oyster beds may rival even successful artificial methods in the ultimate return on outlay. Experiments on the treatment of shell-cultch before distribution in the sea, and novel methods of catching spat in the sea are reasonable problems for research.

The liaison between the oyster cultivator and the Fisheries Department is rendered difficult by the private or semi-private nature of most oysterfisheries, but mutual benefit would undoubtedly follow if a young Government oyster-biologist were assigned the special duty of studying and conducting continuous researches on oyster culture and its problems in all parts of Great Britain. The biologist would be able to help the practical man in everything relating to biology, such as sex, spawning, development, spatfall, feeding, exposure dangers, etc., and in return would learn a great deal about the bionomics of the oyster in its relation to culture, ${ }^{16}$ the local problems in oyster culture, and would eventually become a beneficent expert.

\section{REFERENCES}

1. Spawning. Orton, Jour. M.B.A., 14, $222 ; 1926$

2. Culture. Orton, Report on a Survey of the Fal Estuary Oyster Beds, etc., Falmouth, 63, 22; 1926 .

3. Spawning Epoch. Orton, Jour. M.B.A., 14, Fig. 3, $210 ; 1926$

3. Spawning Epoch. Orton, Jour. M.B.A., 14, Fig. 3, 210; 1926.

4. Blacksick Testing. Orton, Fish Trades Gazette, June 30,

5. Laying Cultch. Orton, Ibid., 14.3, 621; 1927.

6. Laying Cultch. Orton, Ibid., 14, 3, 621 ; 1927. 1927 , in the press.

8. Shell-growth. Havinga, Jour. du Conseil. Int., Copenhagen, 3 , 2,$231 ; 1928$.

9. Food and Fattening. Savage, Fish. Invest., London, 8, 1 ; 1925.

10. Food and Fattening. Savage, Fish. Invest., London, 8, $1 ; 1925$.

11. Plankton Maxima. Lebour, Ibid. 11, 2, 141; 1917.

12. Food Reserves. Russell, Fish. Invest., London, 6, 1, 7; 1923

13. Rearing Larvæ. Allen and Nelson, Jour. M.B.A., 8, 421 ; 1907. 14. Artificial Purification and Production. Dodgson, Fish. Invest. London, 10, 1, 346; 1928.

15. Food Limiting Factors, Atkins, Jour, du Conseil. Int., Copenhagen, 1,$3 ; 1926$.

16. Bionomics and General. Orton, Fish. Invest., London, 6, 3 and 4 ; $1923-4$.

17. Purity. Orton, Jour. Roy. San. Inst., 49, 263; 1928.

\title{
Vitamin D and the Structure of Human Teeth.
}

$\mathrm{I}^{\mathrm{N}}$ $\mathrm{N}$ a recent review in Nature (Vol. 121, p. 325 ; 1928) on the influence of diet upon the teeth, reference was made to the work of M. Mellanby and her collaborators on the effect of diet on the structure of the teeth and on the incidence of caries. More recently the same author has brought forward evidence indicating a definite relationship between structure and the incidence of caries, and has also shown that it is possible to arrest the spread of this condition by suitable alterations in the diet (M. Mellanby, Brit. Dental Jour., Dec. 15, 1927 ; M. Mellanby and C. L. Pattison, Brit. Med. Jour., vol. ii, p. 1079 ; 1928).

An analysis of the results obtained from the

No. 3093, VoL. 123] 
microscopic examination of sections of deciduous teeth showed that only 372 out of 1036 sectioned were normal or nearly normal in structure : 27 per cent of these had carious cavities; on the other hand, of the 664 which showed definite defects of structure, or hypoplasia, no less than 85 per cent were carious. The relationship held with each individual type of tooth: thus the incisors, which are usually the best calcified, showed the lowest incidence of caries, whilst the second molars, which are the worst calcified, were the most susceptible. A similar relationship between structure and caries was observed in the examination of 266 permanent teeth. About 10 per cent of each of the different type of teeth appeared to be exceptions to this relationship, a well-calcified tooth showing caries or vice versa. Apart from the fact that some of these exceptions may be more apparent than real, since the classification of a tooth depends on the structure of the part not affected by caries, and this may be well calcified, the disease having commenced in the badly calcified portion, there is a further factor to be taken into account, the possible change in the resistance of the tooth after eruption. Analysis of the structure of the secondary dentine formed in response to disease or injury showed that, in two-thirds of these exceptions, the presence or absence of caries could be correlated with a poorly formed or a well calcified secondary dentine respectively. This latter observation has a further importance in that it indicates that the resistance of the teeth can be changed after eruption by variations in the degree of calcification of the newlyformed dentine : one factor, and probably the most important, is the diet.

In previous investigations, Mellanby and Pattison have shown that diets favourable to calcification limited the initiation and spread of caries in cbildren and frequently caused a hardening of teeth in which caries had started. In these experiments the diets were improved by giving milk, eggs, and cod-liver oil, thus supplying both vitamins $A$ and D, or were made less satisfactory by increas-. ing the oatmeal content or cutting down the vitamin intake. The present work was undertaken to see whether the good effect of cod-liver oil, for example, was due to its vitamin $\mathrm{A}$ or vitamin $\mathrm{D}$ content: it appears to show that vitamin $\mathrm{D}$ has a marked influence in preventing the spread of caries in children and in promoting its arrest, whilst vitamin A probably has no, or only a slight, effect.

The work described deals with the influence of vitamin $D$, supplied in the form of irradiated ergosterol (1 to 4 c.c. radiostol solution daily). A group of 21 children was placed on a complete average diet, supplemented by the addition of the irradiated ergosterol : the test lasted twenty-eight weeks and the amount and extent and degree of hardness or softness of each carious area were noted in each child at the beginning and end of the experiment. The average age of the children was less than six years. The results obtained were somewhat better than in the previous tests and showed that the addition of the vitamin $D$ had a pronounced effect in preventing the initiation of new carious foci, limiting the spread of the disease, and apparently arresting its progress in many cases. Owing to the younger age of the children of this group, however, somewhat better results might be expected, since there is presumably less interference with the pulp tissue of the teeth by the natural processes of root absorption which occur at a later age.

When only the results obtained with children less than six years of age in the previous tests were compared with those of the present experiment, it was found that the radiostol supplement was only slightly more effective than the addition of cod-liver oil, extra eggs, and milk to the diet. Thus the average number of teeth per child showing initiation or increase of caries was $1 \cdot 0$ and 1.4 respectively in these two groups; on the diet containing little fat soluble vitamins and additional oatmeal the figure was 5.0 teeth per child; whilst on a diet containing no oatmeal and only a moderate quantity of fat soluble vitamins it was $3 \cdot 3$. The average amount of hardening or arrest of caries per child was, in the four groups, $3 \cdot 9,3 \cdot 7,0 \cdot 2$, and $1 \cdot 2$ respectively. Put in another way, the 21 children had 185 carious teeth at the beginning of the investigation: 4 new points appeared during the experiment, 2 in one child : 16 areas showed some spread of the disease, 4 being found again in one child, who was apparently given too little of the irradiated ergosterol. In the majority of the teeth the soft and active caries was in course of arrest, or had actually been arrested, so far as could be ascertained. Microscopic examination of some of these teeth indicated that the process of healing was accompanied by the laying down of wellcalcified secondary dentine.

If these results can be confirmed in adults, they will be of great importance owing to the widespread prevalence of caries among civilised populations to-day. In a recent review on the subject of the influence of diet upon the teeth, M. Mellanby discusses the question whether the incidence of caries can be explained by the nature of the diets consumed, and concludes that such may indeed be the case (Physiol. Reviews, vol. 8, p. $545 ; 1928$ ). The two factors which favour the development of caries are the consumption of large quantities of cereals and the small intake of the foodstuffs which contain vitamin D, milk, butter, cheese, and eggs. If an inadequate intake of this vitamin is only a partial cause of the prevalence of caries, this deficiency must be very widespread amongst all grades of society in civilised nations to-day.

It will be of great interest to see if the spread of caries can be prevented by the administration of irradiated ergosterol in some form to adults: if, as seems probable, this will be the case, then a simple method of preventing dental decay will be available and will be a great stimulus to an increased consumption of milk and milk products, with further benefits to health and well-being, or, for those who prefer it, the diet can be supplemented by a synthetic vitamin $\mathrm{D}$ preparation. 